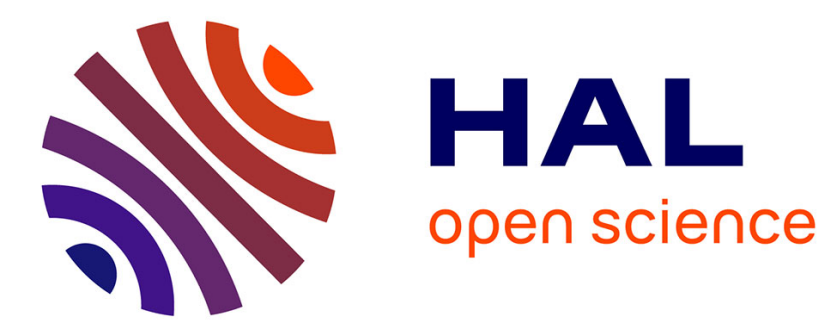

\title{
Susceptibility of non-crystalline ferromagnetic FeF2
}

F.J. Litterst

\section{To cite this version:}

F.J. Litterst. Susceptibility of non-crystalline ferromagnetic FeF2. Journal de Physique Lettres, 1975, 36 (7-8), pp.197-199. 10.1051/jphyslet:01975003607-8019700 . jpa-00231187

\section{HAL Id: jpa-00231187 https://hal.science/jpa-00231187}

Submitted on 1 Jan 1975

HAL is a multi-disciplinary open access archive for the deposit and dissemination of scientific research documents, whether they are published or not. The documents may come from teaching and research institutions in France or abroad, or from public or private research centers.
L'archive ouverte pluridisciplinaire HAL, est destinée au dépôt et à la diffusion de documents scientifiques de niveau recherche, publiés ou non, émanant des établissements d'enseignement et de recherche français ou étrangers, des laboratoires publics ou privés. 


\title{
SUSCEPTIBILITY OF NON-CRYSTALLINE FERROMAGNETIC FeF $_{2}$
}

\author{
F. J. LITTERST
}

Physik Department der Technischen Universität München

D-8046 Garching, James-Franck Str., Germany

(Reçu le 20 mars 1975, révisé le 7 mai 1975, accepté le 12 mai 1975)

\begin{abstract}
Résumé. - On peut décrire la susceptibilité magnétique de $\mathrm{FeF}_{2}$ non cristallin par une loi de Curie-Weiss entre $25 \mathrm{~K}$ et $150 \mathrm{~K}$. On trouve une température de Curie paramagnétique $\theta=(22 \pm 1) \mathrm{K}$ et un moment effectif $p_{\text {eff }}=(5,2 \pm 0,1) \mu_{\mathrm{B}}$. Entre $15 \mathrm{~K}$ et $20,5 \mathrm{~K}$ l'aimantation varie avec la température et le champ, indiquant un comportement superparamagnétique. Aux températures inférieures, l'aimantation montre de l'hystérésis et une rémanence qui dépend faiblement du temps. Les moments approchant $4 \mu_{\mathrm{B}} / \mathrm{Fe}^{2+}$ impliquent que l'état ordonné est ferromagnétique.

Abstract. - In the temperature range $150 \mathrm{~K}>T>25 \mathrm{~K}$ the magnetic susceptibility of noncrystalline $\mathrm{FeF}_{2}$ can be described by a Curie-Weiss law. A paramagnetic Curie temperature of $\theta=(22 \pm 1) \mathrm{K}$ and an effective moment of $p_{\text {eff }}=(5.2 \pm 0.1) \mu_{\mathrm{B}}$ are found. Temperature and field dependence of the magnetization between $15 \mathrm{~K}-20.5 \mathrm{~K}$ indicate superparamagnetic behaviour. At lower temperatures the magnetization shows hysteresis and a slightly time dependent remanence. The observation of moments which approach $4 \mu_{\mathrm{B}} / \mathrm{Fe}^{2+}$ implies that the ordered state is ferromagnetic.
\end{abstract}

Non-crystalline $\mathrm{FeF}_{2}$ can be prepared by condensation of a molecular beam of $\mathrm{FeF}_{2}$ on to a He-cooled substrate in a vacuum of $\sim 10^{-8}$ torr. We have shown previously by Mössbauer spectroscopy that noncrystalline $\mathrm{FeF}_{2}$ becomes magnetically ordered below $\sim 21 \mathrm{~K}$ [1]. This is in contrast to the Néel temperature $T_{\mathrm{N}}=78 \mathrm{~K}$ found for crystalline antiferromagnetic $\mathrm{FeF}_{2}$ [2]. The non-crystalline samples of $\mathrm{FeF}_{2}$ are converted into the crystalline state only at temperatures above $\sim 800 \mathrm{~K}$ [3]. It is thus possible to warm such samples to $300 \mathrm{~K}$, carefully brush the amorphous material from the substrate, and then transfer the powder under an inert atmosphere into a magnetometer (Foner type, vibrating sample method) without any structural changes taking place. The measured susceptibility in a field of $H=1250 \mathrm{Oe}$ and the temperature range $150 \mathrm{~K}>T>25 \mathrm{~K}$ can be described by a Curie-Weiss law (Fig. 1). An extrapolated paramagnetic Curie temperature of $\theta=(22 \pm 1) \mathrm{K}$ was found together with $p_{\text {eff }}=(5.2 \pm 0.1) \mu_{\mathrm{B}}$.

The derived value $g=2.12 \pm 0.05$ of non-crystalline $\mathrm{FeF}_{2}$ is only slightly larger than $g=2.10 \pm 0.05$ for crystalline $\mathrm{FeF}_{2}$ [4]. The magnitude and temperature dependence of the quadrupole splitting and the magnitude of the magnetic hyperfine interaction as derived from the Mössbauer spectra indicate a less complete quenching of the orbital momentum in non-crystalline $\mathrm{FeF}_{2}$ compared to the crystalline phase [1, 3]. A simple

$\left(^{*}\right)$ Work supported in part by Bundesministerium für Forschung und Technologie.

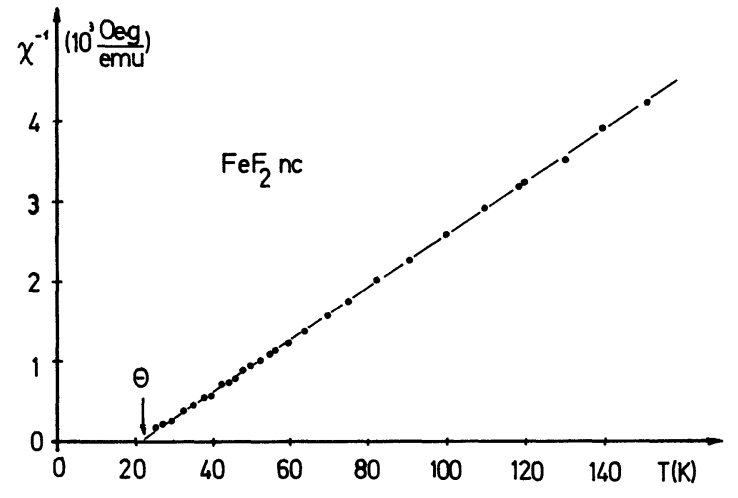

FIG. 1. - Inverse susceptibility of non-crystalline $\mathrm{FeF}_{2}$ against temperature.

perturbational treatment for the crystal electric field levels shows that an increase of the rhombic distortion at $\mathrm{Fe}^{2+}$ in the non-crystalline phase leading to a decrease of the splitting between the ground state and the first excited orbital state from $\sim 700 \mathrm{~cm}^{-1}$ (crystalline phase [5]) to $\sim 500 \mathrm{~cm}^{-1}$ can explain the increase of orbital momentum. It would, however, only cause an increase of $\sim 0.03$ in $g$-factor which agrees well with the data found.

In figure 2 the magnetization curves between 15$20.5 \mathrm{~K}$ are plotted as $\left(M \times M_{\mathrm{s}}(T=0)\right) / M_{\mathrm{s}}(T)$ against $H \times M_{\mathrm{s}}(T) /\left(T \times M_{\mathrm{s}}(T=0)\right)$. The approximate ratios of the spontaneous magnetizations

$$
M_{\mathrm{s}}(T) / M_{\mathrm{s}}(T=0)
$$




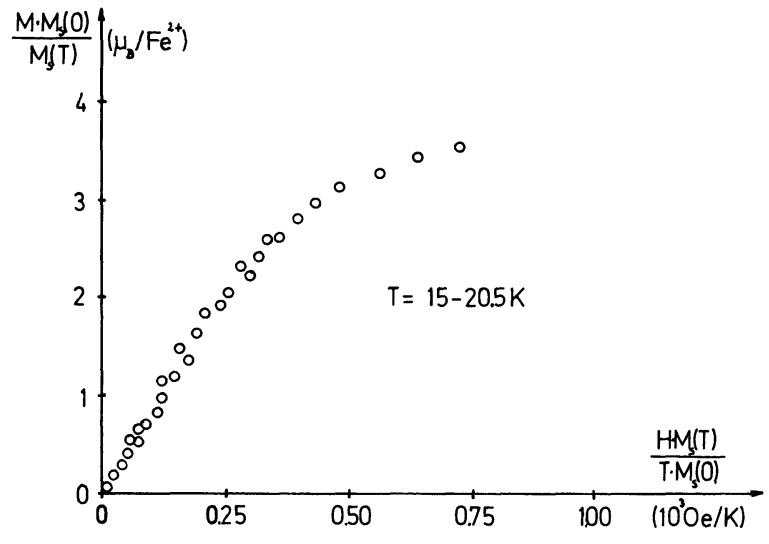

FIG. 2. - Plot of the magnetization $M \times M_{\mathrm{S}}(T=0) / M_{\mathrm{S}}(T)$ against $H \times M_{\mathrm{s}}(T) /\left(T \times M_{\mathrm{s}}(T=0)\right)$

were taken to be identical to the ratios

$$
H_{\mathrm{hf}}(T) / H_{\mathrm{hf}}(T=0)
$$

as determined by the hyperfine splitting of the Mössbauer resonance [1] (Fig. 3). The magnetization curves follow nearly superposing Langevin functions, a behaviour which is typical of superparamagnetism [6]. The large magnetic moments per $\mathrm{Fe}^{2+}$ ion (approaching $4 \mu_{\mathrm{B}}$ ) indicate superparamagnetism of a ferromagnetic configuration rather than superparamagnetism in poorly compensated antiferromagnetic crystallites. If we attribute this magnetic behaviour to an ensemble of non-interacting particles, with all spins coupled ferromagnetically from the slopes of the Langevin functions we can derive a mean moment of $(115 \pm 40) \mu_{\mathrm{B}}$ per saturated ferromagnetic particle corresponding to $\sim 30 \pm 10$ molecules and a volume of $\sim(1200 \pm 400) \AA^{3}$ per particle. The interatomic distances are assumed to be identical to those of crystalline $\mathrm{FeF}_{2}$. The errors are mainly due to the inaccurate knowledge of $M_{\mathrm{s}}(T)$ near $T_{\mathrm{c}}$. The mean blocking temperature $T_{\mathrm{B}}=15 \pm 2 \mathrm{~K}$ observed in these magnetization measurements (typical time of observation

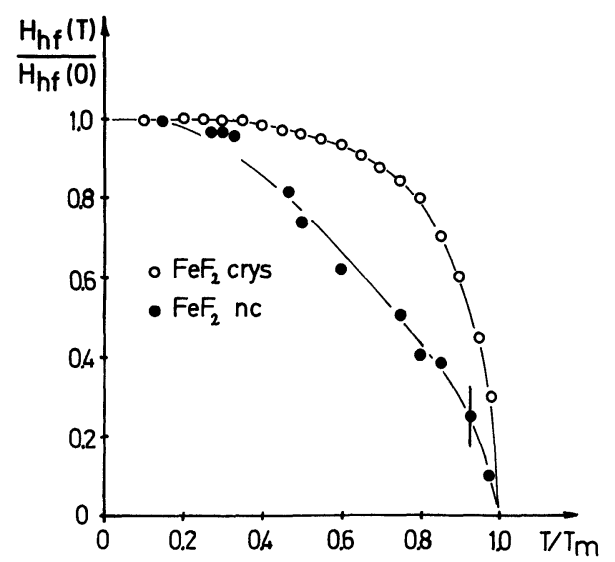

FIG. 3. - Normalized hyperfine magnetic field $H_{\mathrm{hf}}$ of noncrystalline $\mathrm{FeF}_{2}$ [1] and of crystalline $\mathrm{FeF}_{2}$ ([2] and own data) derived from hyperfine splitting of the Mössbauer resonance plotted against $T / T_{\mathrm{m}} . T_{\mathrm{m}}$ is the Curie temperature $T_{\mathrm{C}}=21 \mathrm{~K}$ for non-crystalline $\mathrm{FeF}_{2}$, and the Néel temperature $T_{\mathrm{N}}=78 \mathrm{~K}$ for crystalline $\mathrm{FeF}_{2}$, respectively. $\sim 1 \mathrm{~s})$ allows an estimate of the anisotropy density $K$ of the superparamagnetic particles. Using a simple model which applies only for non-interacting particles of uniaxial symmetry (certainly an oversimplification of the present case) [7] we may write :

$$
\tau=\frac{\widehat{M}_{\mathrm{s}}}{\gamma K} \sqrt{\frac{k T_{\mathrm{B}}}{K \cdot V}} \exp \left(K \cdot V / k T_{\mathrm{B}}\right) .
$$

Here $\gamma$ is the gyromagnetic ratio and $\widehat{M}_{\mathrm{s}}$ is the saturation magnetization per unit volume. We then find $K \simeq(4.0 \pm 1.5) 10^{7} \mathrm{erg} / \mathrm{cm}^{3}$ which is about one third of the crystalline anisotropy of crystalline antiferromagnetic $\mathrm{FeF}_{2}$ [8].

At even lower temperatures the magnetization curves show hysteresis and remanence. The remanence decreases slightly with time. The value found for the remanence at $4.2 \mathrm{~K}, M_{\mathrm{r}}=(1.5 \pm 0.5) \mu_{\mathrm{B}}$ is somewhat less than $2 \mu_{\mathrm{B}}$ which is expected for an ensemble of randomly oriented single domain particles of axial symmetry [9]. The magnitude as well as the time dependence of $M_{\mathrm{r}}$ indicate that due to a distribution of particle sizes (and probably of $K$, too) there is still a small amount of superparamagnetic, or at least nearly superparamagnetic, particles present at the lowest temperatures.

This observation of superparamagnetism is not contradictory to Mössbauer data which show an abrupt onset of magnetic hyperfine splitting below $21 \mathrm{~K}$, since nuclear Larmor precession is still faster than the flipping of magnetization of a superparamagnetic particle. Since non-crystalline samples prepared by vapour quenching are likely to contain voids, a detailed discussion of the magnetization curves at low temperatures is precluded by the ill-defined demagnetization factor.

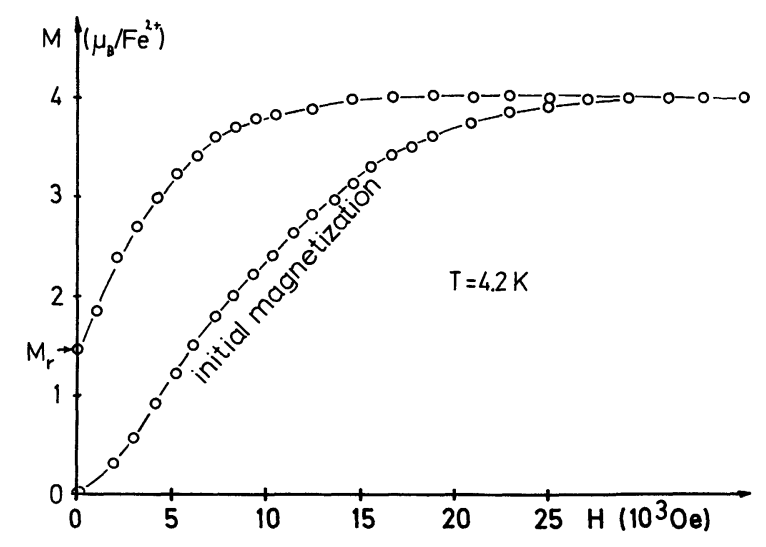

FIG. 4. - Magnetization of non-crystalline $\mathrm{FeF}_{2}$ at $4.2 \mathrm{~K}$.

If the molecular beam of $\mathrm{FeF}_{2}$ is quenched on to a $\mathrm{N}_{2}$-cooled substrate, then the inverse high temperature susceptibility extrapolates to a Curie-Weiss temperature $\theta \simeq-120 \mathrm{~K}$ which comes close to that found for crystalline $\mathrm{FeF}_{2}$ [4]. Below $78 \mathrm{~K}$, however, the susceptibility still increases. Values of about 
$2.5 \times 10^{-3} \mathrm{emu} / \mathrm{g} \times$ Oe are found at $10 \mathrm{~K}$ which is more than ten times the corresponding value for crystalline antiferromagnetic $\mathrm{FeF}_{2}$. At lower temperatures the susceptibility decreases. If the samples are cooled to $4.2 \mathrm{~K}$ in an applied field of $5 \times 10^{4}$ Oe a thermoremanence of $\sim 0.1 \mu_{\mathrm{B}}$ per $\mathrm{Fe}^{2+}$ is found which vanishes upon heating to $18 \mathrm{~K}$. The temperature dependence of the magnetization and the thermoremanence can be interpreted in terms of superparamagnetism of small antiferromagnetic particles [10] which are not totally compensated sublattices of crystalline $\mathrm{FeF}_{2}$. The Mössbauer spectra further support the picture that in this case small particles of the usual crystalline structure of $\mathrm{FeF}_{2}$ are formed. The samples are still «X-ray amorphous». The ferromagnetic properties of non-crystalline $\mathrm{FeF}_{2}$ prepared by quenching to He-temperature, therefore, cannot be attributed to surface effects of fine particles alone. The breakdown of antiferromagnetism must be correlated with the distortion of the $135^{\circ}$ bond angle between $\mathrm{Fe}^{2+}-\mathrm{F}^{-}-\mathrm{Fe}^{2+}$ connecting the corner $\mathrm{Fe}^{2+}$ with the central $\mathrm{Fe}^{2+}$ in the rutile cell of crystalline $\mathrm{FeF}_{2}$. This bond is responsible for the strong antiferromagnetic superexchange coupling in crystalline $\mathrm{FeF}_{2}$. A suggested explanation of the ferromagnetic coupling is superexchange via nearly $90^{\circ} \mathrm{Fe}^{2+}-\mathrm{Fe}^{-}-\mathrm{Fe}^{2+}$ bonds similar to the exchange coupling between $\mathrm{Fe}^{2+}$ ions inside layers of crystalline $\mathrm{FeCl}_{2}$ [11]. Although these magnetic data show that amorphous ferromagnetic $\mathrm{FeF}_{2}$ has the same magnetic behaviour as an ensemble of ultra-fine particles, more independent evidence for the presence of these particles is desirable. Such behaviour could eventually be typical of some amorphous ferromagnets. The radial distribution function will be determined in order to decide whether an amorphous cluster model with particles of the proposed size or a random network model can give a better description of the non-crystalline structure. Resistivity- measurements on freshly deposited non-crystalline samples will be performed to ascertain their insulating character.

Acknowledgment. - Many helpful discussions with G. M. Kalvius are gratefully acknowledged.

\section{References}

[1] Litterst, F. J., Kalvius, G. M., Boyle, A. J. F., Proc. 19th Conf. Magnetism and Magnetic Materials (1973) Boston, AIP Conf. Series 18, 616 (Graham C. D. Jr, Rhyne J. J., eds).

[2] Wertheim, G. K., Buchanan, D. N. E., Phys. Rev. 161 (1967) 478.

[3] Litterst, F. J., Kalvius, G. M., Boyle, A. J. F., J. Physique Colloq. 12 (1974) C 6-403.

[4] Foner, S., Proc. Int. Conf. Magnetism, Nottingham (1964) London, Inst. of Physics and the Phys. Soc., p. 438.
[5] Dale, B. W., J. Phys. C 4 (1971) 2705.

[6] Jacobs, I. S., BeAN, C. P., in Magnetism III (Acad. Press. London, New York), eds. Rado, Suhl 1963, p. 271

[7] Aharoni, A., Phys. Rev. 177 (1969) 793.

[8] Lines, M. E., Phys. Rev. 156 (1967) 543.

[9] Morrish, A. H., in The Physical Principles of Magnetism (Wiley, New York) 1965, 340-360.

[10] Néel, L., J. Phys. Soc. Japan 17 (1962) 676.

[11] Kanamori, J., J. Phys. \& Chem. Solids 10 (1959) 87. 